\title{
Soleus accessorius, an anomalous muscle in a young athlete: case report and analysis of the literature
}

\section{A Christodoulou, I Terzidis, K Natsis, I Gigis, J Pournaras}

Br J Sports Med 2004;38:e38 (http://www.bjsportmed.com/cgi/content/full/38/6/e38). doi: 10.1136/bjsm.2004.012021

The soleus accessory muscle is a rare anatomical variation. It usually appears as a soft tissue mass and may be mistaken for a tumour or an inflammatory lesion. The differential diagnoses include ganglion, lipoma, haemangioma, synovioma, and sarcoma. This is a report of such a muscle mass in the leg of a young athlete with 16 years follow up. A review of the English literature on this subject is also presented.

S oleus accessory muscle is a rare anatomical variation. It usually appears as a soft tissue mass bulging medially between the distal part of the tibia and the Achilles tendon and may be mistaken for a tumour or an inflammatory lesion. The young age of the patients reported in the literature supports the theory that the accessory soleus muscle is of congenital origin. The delay of onset of symptoms until adolescence is probably due to the increase in muscle mass and muscle activity. ${ }^{1}$ Muscle hypertrophy, especially in athletes, changes the outward appearance of the calf region. The differential diagnosis includes ganglion, lipoma, haemangioma, synovioma, and sarcoma. ${ }^{12}$ Twenty five per cent of cases are asymptomatic and no treatment other than observation is needed. ${ }^{2}$ In symptomatic patients, fasciotomy or excision is the treatment of choice. We present a case of such a muscle mass in the leg of a young athlete with 16 years follow up. In addition, we review the English literature on this subject.

\section{CASE REPORT}

A 17 year old male basketball player in a professional team presented in 1986 with a soft tissue mass posteromedial to the left ankle. This mass had been noted by the patient about two years previously, but was only symptomatic over the preceding four months, especially after exercise or training. He experienced pain in the area gradually increasing with activity (running and/or jumping). The symptoms were relieved by rest.

On physical examination, there was a noticeable bulging mass that was $9 \times 5 \times 2 \mathrm{~cm}$ in size lying posterior to the medial malleolus between the flexor tendons of the foot and the calcaneal tendon, soft on palpation, non-fluctuating, adhering to deep structures, and painless. There were no signs of inflammation in the area, and pain could not be elicited on palpation. The patient showed a full range of ankle and subtalar movements.

The other foot did not show any deformity. Roentgenograms were normal. Despite rest and anti-inflammatory drugs, the patient remained symptomatic. Needle aspiration was negative. Magnetic resonance imaging (MRI) was not available in our department at that time, and we decided to carry out exploratory surgery of the area with the most likely diagnosis of lipoma.
Surgery was performed under general anaesthesia. A large muscular mass (fig 1) with well defined borders was noted occupying the Kager's triangle. This was located posterior to the medial malleolus between the flexor tendons of the foot and the calcaneal tendon. Macroscopically, it appeared to be muscular tissue with a proximal thin tendinous insertion in the superficial anterior fascia of the soleus muscle and a distal thick tendinous insertion in the "tuber calcanea" anteromedial to the Achilles tendon.

The musculotendinous insertion was not explored proximally because of operative restrictions. Blood supply was derived from the posterior tibial artery by two arteries. One accessory branch of the tibial nerve was responsible for the innervation (fig 2). Histopathology confirmed that it was normal muscle tissue.

After the operation, the aching and swelling in the leg that developed with activity was resolved and the patient returned to full activity eight weeks later. He was free of symptoms at the last examination 16 years after the operation, without any evidence of the condition in the right leg.

\section{DISCUSSION}

Accessory soleus muscle has the characteristic findings of a normal muscle in an abnormal location. Gruvelhier (cited by Percy and Telep" ${ }^{3}$ ) first named this muscle "supernumerary soleus" in 1843, and in 1871 Pye Smith (cited by Brodie et $\mathrm{al}^{2}$ ) described an anomalous muscle in the leg named "soleus secundus". This anomaly has been considered to be rare, but it may be more common than previously recognised.

Although present from birth, it manifests in the late teens because of muscle hypertrophy secondary to increased physical activity, especially in athletes. ${ }^{4}$

The accessory soleus, peroneus quartus, and flexor digitorum longus accessories are anomalous muscles of the lower extremity and are more common than once thought. ${ }^{5}$ The embryological origin of the accessory soleus muscle is due to early splitting of a single anlage of the soleus muscle, with the development of an extra fasciculus or even a supernumerary muscle. ${ }^{6}$ A supernumerary soleus muscle is extremely rare and therefore may not be the primary cause of clubfoot. If a supernumerary soleus muscle is found in a clubfoot, it may, however, increase the deformity and prevent correction, especially of the varus, but also of the equinus deformity. ${ }^{78}$ Three cases of a supernumerary soleus muscle have been reported by Dunn, ${ }^{9}$ one case by Danielsson and Theander, ${ }^{10}$ and two cases by Danielsson. ${ }^{11}$

This accessory muscle (typical location) arises from the anterior surface of the soleus, which corresponds to our case, from the soleal line of the tibia or from the fibula and is attached with a separate tendon to the calcaneus anteromedial to the tendon Achilles. The innervation of this muscle by two nerves from the tibial nerve ${ }^{12}$ has been described, but in

Abbreviations: $\mathrm{CT}$, computed tomography; $\mathrm{MRI}$, magnetic resonance imaging 


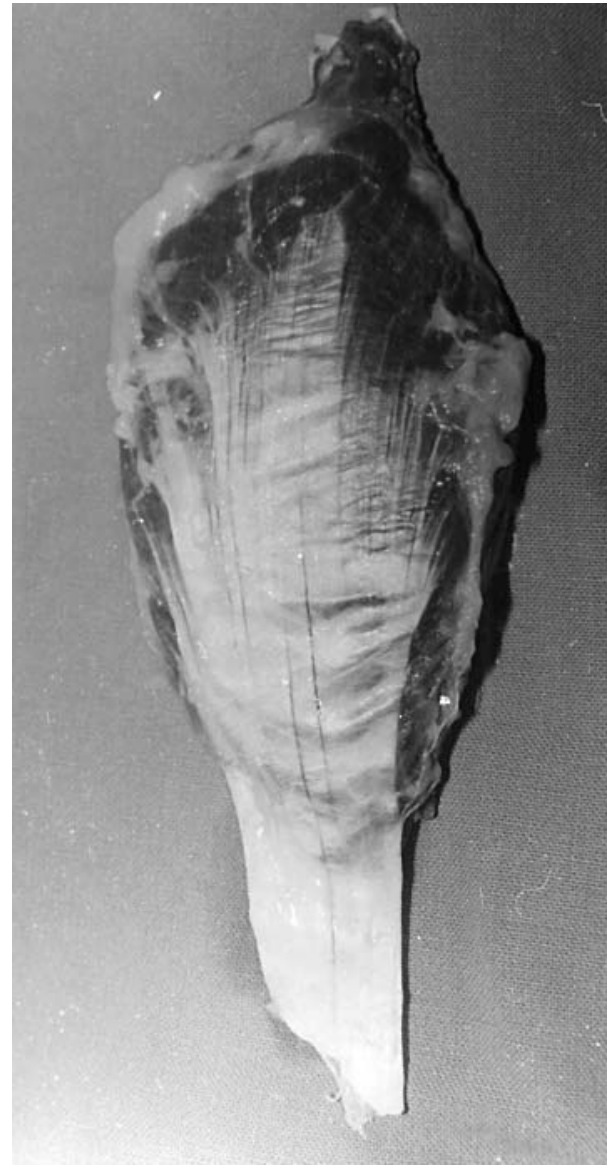

Figure 1 The excised accessory soleus muscle. The musculotendinous proximal insertions to the soleus and the distal tendinous insertion to the calcaneus.

our case only one branch of the tibial nerve was identified as its nerve supply (fig 2).

Lorentzon and Wirell ${ }^{13}$ found four different varieties of insertion in four cases of accessory muscle: along the Achilles tendon, fleshy to the upper surface of the calcaneus, fleshy to the medial surface of the calcaneus, and finally by a separate tendon to the upper surface to the calcaneus, which corresponds to our case (fig 1). A fifth type of insertion characterised by a separate tendon inserting on the medial surface of the calcaneus is described by Yu and Resnick. ${ }^{14}$ Del Sol et $a l^{15}$ found two accessory muscles, both in male patients, with different insertions. In one case, the muscle originated from the soleus muscle and was inserted in the superior aspect of the calcaneus in front of the Achilles tendon. The other case originated from the anterior fascia of the soleus muscle and was inserted in the medial aspect of the calcaneus. These variations may be important in the planning of operative treatment.

The correct diagnosis can normally be made from the history, the physical findings, and the roentgenographic findings. ${ }^{3}$ Before the advent of MRI, plain radiographs, ultrasound, and computed tomography (CT) scans were used to diagnose an accessory soleus. ${ }^{11}{ }^{16-18}$ Plain radiography generally shows soft tissue swelling between the deep compartment musculature and the tendon Achilles, which obscures or obliterates Kager's triangle on the lateral radiograph of the ankle. Ultrasound shows a mass identical with the adjacent muscles. The characteristic appearances on CT/ MRI allow a confident diagnosis without the need to resort to biopsy. ${ }^{5}$ MRI allows accurate diagnosis of an accessory soleus

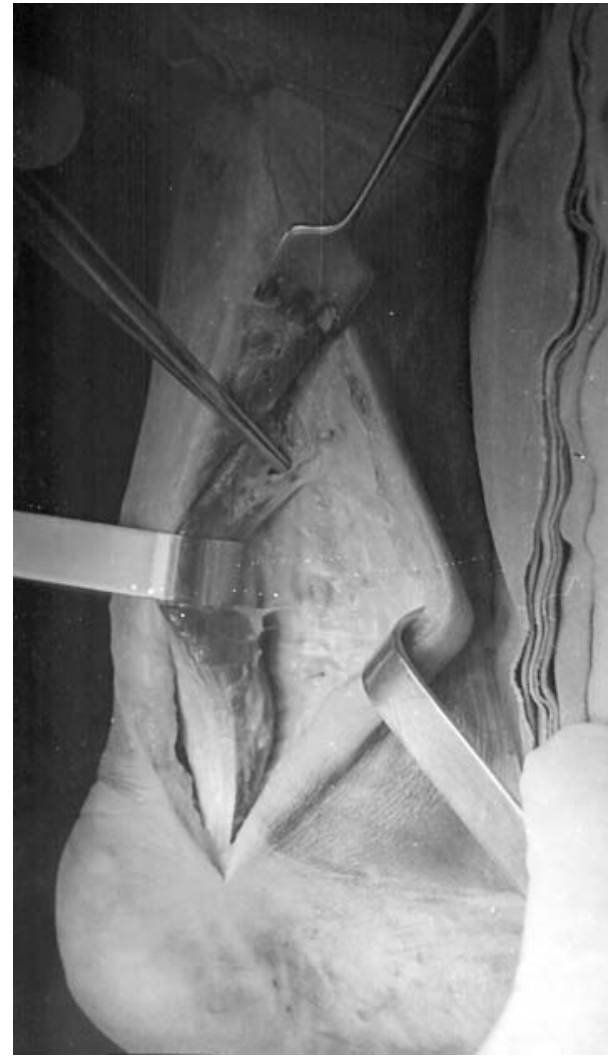

Figure 2 The innervation and concomitant vessels of the muscle: artery, veins, and nerve proximally; artery and veins distally.

muscle because normal muscle has a distinctly different signal intensity from that of both abnormal muscle and soft tissue tumours. ${ }^{519}$ If the patient is asymptomatic, no treatment is required. If pain or other discomfort is provoked such as swelling and/or functional disorder (varus or equinovarus) especially during or after exercise, surgical treatment is recommended by means of fasciotomy or excision of the accessory muscle. ${ }^{2}$ A fasciotomy may be required to relieve an exercise induced compartment syndrome. If nerve compression or claudication is the patient's main complaint, total excision of the accessory muscle may be needed..$^{13} 2021$ Dokter and Linclau ${ }^{22}$ have described treatment of this condition by ligating the feeding artery, which led to atrophy of the muscle, but this procedure requires further intervention such as angiography. We believe that this method is not ideally suited, especially when other options such as surgical excision are more readily available, especially in young professional athletes who need early and definite pain-free return to athletic activity.

\section{ANALYSIS OF THE LITERATURE}

Thirty eight reports were located in the literature. Twenty one of them were case reports, ${ }^{4-8}{ }^{16-18} 202124-35$ and 17 were small series $^{1-3}$ 9-11 13-15 192223 36-40 (2-11 patients). There were 76 patients (87 cases) with a mean age of 19.4 years (range 3 months to 66 years): 49 (65\%) were male, 31 (41\%) presented with symptoms in the left leg, 34 (45\%) with symptoms in the right leg, and $11(12 \%)$ with bilateral symptoms.

Most $(65 \%)$ of the patients presented with swelling and pain, and $22 \%$ presented with painless swelling. Four $(5 \%)$ were diagnosed during surgical release for clubfoot deformity $^{5114}$ and one patient (1\%) for equinus deformity. ${ }^{7}$ Accessory soleus was diagnosed in one patient $(1 \%)$ as an 
incidental finding at the time of surgery, ${ }^{7}$ one (1\%) during irrigation and debridement of an open fracture of the tibia, ${ }^{40}$ and in one patient $(1 \%)$ the diagnosis was made clinically after cramping in the calves?

Six of the patients were students, ${ }^{725}$ two were runners, ${ }^{3}{ }^{19}$ two were gymnasts, ${ }^{24}$ and one each of the following: soldier, ${ }^{8}$ sailor, ${ }^{8}$ dancer, ${ }^{3}$ hiker, ${ }^{3}$ soccer player, ${ }^{31}$ and ice hockey player. ${ }^{23}$ The activities and occupations of the other 60 patients were not available. Of the 76 patients reviewed, 23 $(30 \%)$ were evaluated by MRI, 21 (28\%) by CT scan, and 17 $(22 \%)$ by plain radiography only.

In 25 patients fasciotomy was the treatment used, 17 patients underwent exploration, and in 16 patients, complete or partial excision was performed. In four patients, release was the method of choice, and in one patient ligation of the blood supply was used to induce atrophy of the muscle. ${ }^{22}$ In 24 patients, conservative treatment (rest and anti-inflammatory drugs) was proscribed. Most had no symptoms at presentation, and most were seen within the last 10 years when CT and MRI were available.

\section{CONCLUSIONS}

Accessory soleus muscle is a rare anatomical variation in the posteromedial aspect of the ankle. It is an anomalous muscle that mimics soft tissue tumour. It may be a cause of exertional pain and swelling secondary to increased physical activity, especially in athletes. In this situation surgical excision or fasciotomy is necessary.

\section{Authors' affiliations \\ A Christodoulou, I Terzidis, I Gigis, J Pournaras, 1st Orthopaedic \\ Department, Aristotelian University of Thessaloniki, Greece \\ K Natsis, Laboratory of Anatomy, Medical School, Aristotelian University of Thessaloniki}

Correspondence to: Mr Terzidis, Hippocration General Hospital of Thessaloniki, Orthopaedic Department, 36 Emou Str, Thessalonik 54623, Greece; jonterz@otenet.gr

Accepted 29 March 2004

\section{REFERENCES}

1 Romanus B, Lindahl S, Stener B. Accessory soleus muscle. A clinical and radiological presentation of eleven cases. J Bone Joint Surg Am J 1986;68:731-4

2 Brodie JT, Dormans JP, Gregg JR, et al. Accessory soleus muscle. A report of 4 cases and review of literature. Clin Orthop 1997;337:180-6.

3 Percy EC, Telep GN. Anomalous muscle in the leg: soleus accessorium. Am J Sports Med 1984; 12:447-50.

4 Palaniappan M, Rajesh A, Rickett A, et al. Accessory soleus muscle: a case report and review of the literature. Pediatr Radiol 1991;29:610-12.

5 Buschmann WR, Cheung Y, Jahss MH. Magnetic resonance imaging of anomalous leg muscles: accessory soleus, peroneus quartus and the flexor digitorum longus accessorius. Foot Ankle 1991;12:109-16.

6 Gordon SL, Matheson DW. The accessory soleus muscle. Clin Orthop 1973;97:129-32.
7 Bonnel J, Cruess RL. Anomalus insertion of the soleus muscle as a cause of fixed equines deformity. A case report. J Bone Joint Surg [Am] 1969;51:999-1000

8 Chotigavanichaya C, Scaduto AA, Jadhav A, et al. Accessory soleus muscle as a cause of resistance to correction in congenital club foot: a case report. Foot Ankle Int 2000;21:948-50.

9 Dunn AW. Anomalous muscles simulating soft tissue tumors in the lower extremities. A report of three cases. J Bone Joint Surg [Am] 1965:47A: 1397-400

10 Danielsson L, Theander G. Supernumerary soleus muscle. Acta Radiol Diagn Stockh 1981;22:365-8.

11 Danielsson LG, El-Haddad I, Sabri T. Clubfoot with supernummary soleus muscle, report of 2 cases. Acta Orthop Scand 1990;61:371-3.

12 Sekiya S, Kumaki K, Yamada TK, et al. Nerve supply to the accessory soleus muscle. Acta Anat (Basel) 1994;149:121-7.

13 Lorentzon R, Wirell S. Anatomic variations of the accessory soleus muslce. Acta Radiol 1987;28:627-9.

14 Yu JS, Resnick D. MR imaging of the accessory soleus muscle appearance in six patients and a review of the literature. Skeletal Radiol 1994;23:525-8.

15 Del Sol $M$, Junge $C$, Binvignat $O$, et al. The accessory soleus muscle: 2 cases. Rev Med Chil 1989;117:677-81.

16 Assoun J, Railhac JJ, Richardi G, et al. CT and MR of accessory soleus muscle. J Comput Assist Tomogr 1995;19:333-5.

17 Ekstrom JE, Shuman WP, Mack LA. MR imaging of accessory soleus muscle. J Comput Assist Tomogr 1990;14:239-24.

18 Mansberg VJ, Van Niekerk AL. The accessory soleus muscle: a case report and review of the literature. Australas Radiol 1991;35:276-8.

19 Peterson DA, Stinson W, Carter J. Bilateral accessory soleus. A report on four patients with partial fasciectomy. Foot Ankle 1993;14:284-8.

20 Ger R, Sedlin E. The accessory soleus muscle. Clin Orthop 1976;1 16:200-2.

21 Wu KK. Accessory soleus muscle simulating a soft tissue tumor of the posteromedial ankle region. J Foot Surg 1991;30:470-1.

22 Dokter G, Linclau LA. Case report: the accessory soleus muscle: symptomatic soft tissue tumour or accidental finding. Neth J Surg 1981;33:146-9.

23 Paul MA, Imanse J, Golding RP, et al. Accessory soleus muscle mimicking a soft tissue tumor. A report of 2 patients. Acta Orthop Scand $1991 ; 62: 609-11$

24 Knutsen G, Lichtenberg N. Accessory soleus muscle as a tumor in the ankle region. Tidsskr Nor Laegeforen 1993; 1 13:452-3.

25 Wejsflog A, Tokarowski A. Rzadki przypadek. Musculus soleus accessorius hypertrophicus. Chir Narzadow Ruchu Ortop Pol 1975;40:393-5.

26 Graham CE. Accessory soleus muscle [letter]. Med J Aust 1980;2:574-6.

27 Ayala H, De Pablos J, Martinez A. The soleus accessorius muscle. Report of a case. Acta Orthop Belg 1982;48:417-20.

28 Lozach P, Conard JP, Delarue P, et al. A case of an accessory soleus muscle Rev Chir Orthop Reparatrice Appar Mot 1982;68:391-3.

29 Fasel J, Dick W. Accessory muscles in the medial retromalleolar region. Z Orthop Ihre Grenzgeb 1984;122:835-7.

30 Nichols GW, Kalenak A. The accessory soleus muscle. Clin Orthop 1984; 190:279-80.

31 Apple JS, Martinez S, Khoury MB, et al. Case report 376. Skeletal Radiol 1986;15:398-400.

32 Nelimarkka O, Lehto $M$, Jarvinen $M$. Soleus muscle anomaly in a patient with exertion pain in the ankle. A case report. Arch Orthop Trauma Surg 1988; 107:120-1

33 Hansen LB, Broeng L. Accessory soleus muslce. Ugeskr Laeger 1991:153:3090-1.

34 Sundaram S, Baran G. Radiologic case study: accessory soleus muscle. Orthopaedics 1991;14:499-501

35 Vanek J, Fourre D. Accessory soleus muscle. Acta Orthop Belg 1993;59:401-3.

36 Beasley AW. The accessory soleus. Aust N Z J Surg 1979;49:86-8.

37 Nidecker AC, Von Hochstetter A, Fredenhagen H. Accessory muscles of the lower calf. Radiology 1984;151:47-8.

38 Trosko JJ. Accessory soleus. A clinical perspective and report of three cases. $J$ Foot Surg 1986;25:296-300.

39 Mesttdagh H, Champetier J, Mauroy B, et al. The supernumerary muscles of the leg. A report of two cases. Surg Radiol Anat 1990;12:219-23.

40 Chittaranjan BS, Babu NV, Abraham G. Accessory soleus muscle: a problem of awareness. Aust N Z J Surg 1994:64:503-5. 